\title{
From Organizations to Organizational Fields: The Evolution of Civic Innovation Ecosystems
}

\author{
Matthew Claudel
}

\author{
"(The things we fear most in organizations") \\ - fluctuations, disturbances, imbalances - \\ are the primary sources of creativity. \\ Margaret J. Wheatley \\ Author, speaker, and management consultant
}

\begin{abstract}
Contemporary approaches to urban technology emphasize local "innovation ecosystems". Two organizational models - living labs and innovation integrators - are commonly used as hubs to broker these ecosystems. Curiously, both coexist in some cities, allowing a comparison of their impact and an analysis of their development over time and in context. The case studies presented in this article suggest that our analytical frameworks for technology policy may fall short, in that they contemplate only the organizations themselves - the living labs or innovation integrators. The dynamics observed in each city are well articulated, however, in the sociotechnical systems literature. The hub can be understood as a "niche", which fosters radical innovations and new processes. As these prototypes are increasingly deployed and accepted, there is a regime shift, ultimately creating an experimentalist culture that fills the role previously held by the hub. This conclusion is neither a challenge to ecosystem theory nor a critique of innovation policy and its implementation. Rather, I suggest that we must extend these theoretical frameworks, drawing on sociotechnical systems literature to better account for institutions and for systems change as we design policy for urban technology. This article therefore makes a contribution by using a sociotechnical systems lens to explain the evolution of local urban innovation ecosystems.
\end{abstract}

\section{Introduction}

Urban technology is a growing area of economic, social, and political opportunity, but the appropriate model for creating it remains a debate in both academia and practice. We are now many years into the urban technology movement - the ideas of smart cities, living labs, urban technology, e-government, etc. have become familiar. The contemporary innovation ecosystem approach emphasizes the need for a "hub" organization that coordinates local stakeholders (for example, by facilitating idea-transfer into and out of city government, translating between technologists and non-profits, hosting prototyping facilities, or pooling funds). Two main hub models have emerged in recent years - living labs and innovation integrators. This article evaluates the operations of these two organization models, and their dynamic change over time, using a unique case design: cities where both co-exist.
At this stage in the history of urban technology policy, it is important to understand the success of various approaches, as they have been deployed in real cities and matured over time. To that end, this article presents an analysis of eight organizations: four living labs and four innovation integrators in four different cities. Using semi-structured interviews with stakeholders inside and outside the organizations, I characterize the structure, typical projects, and outcomes of each organization. From this analysis, I draw three primary conclusions. First, living labs and innovation integrators have evolved since their founding, following one of three paths: they specialize, split into multiple entities, or shift to a mediating role. This is not a failure of the organizations, but rather a result of a change in the surrounding urban context. As the ecosystem becomes more familiar with urban technology, there is less need for a "hub", and the organizations are free to specialize to their strengths. Developing urban technology is no 


\section{From Organizations to Organizational Fields: The Evolution of Civic Innovation Ecosystems Matthew Claudel}

longer the responsibility of a single hub organization, but is now a collaborative goal shared by multiple actors, project by project. Second, city governments are successfully working with their local ecosystems independently, rather than procuring urban technology from large IT firms or relying on a central innovation hub (the ecosystem hub approach). Finally, several specific barriers to urban technology (such as access to resources, networking, and testing in public space), which were initially lowered by living labs and innovation integrators, are now mitigated by cross-sector networks, shared culture, and mutual trust. It is difficult to frame the observed evolution of living labs and innovation integrators purely within the theoretical framework of urban technology systems. However, by considering the city as a sociotechnical system - beyond a narrow analysis of the organizations themselves - it becomes clear that the hubs' early projects created conditions for a more open, distributed mode of working among various stakeholders.

\section{Innovation Ecosystems and Hub Organizations}

The original computing- and efficiency-oriented vision of smart cities has been redirected (Stratigea et al., 2015). A contemporary approach to urban technology directly addresses many of the critiques of the smart city (Curley, 2016), now accounting for non-economic, non-technological outcomes, and spanning sectors: public, private, academic, and citizen (Vanolo, 2014). In this "innovation ecosystem" framework, the definition and development of projects both involve many and varied stakeholders (Snow et al., 2016). Proponents have argued that this can improve outcomes, for example, by revealing local conditions during problem definition, leveraging community expertise during project development, or accounting for livelihoods as the result is integrated (Desouza \& Bhagwatwar, 2012; Voss \& Carolan, 2012). This is because urban technology is uniquely concerned with the supply side (participation, innovation) and the demand side (use, integration), in that it links local actors, institutions, and places in the fulfilment of societal functions (Cohen et al., 2016; Kontokosta, 2016). Independent of technological or economic outcomes, the innovation process itself can generate collective social benefit through empowerment, equity of access, and capacitybuilding (Booher \& Innes, 2002; Gerometta et al., 2005; Shin \& Shin, 2016).

Consider Amsterdam's Biogas Boat as an example of the urban innovation ecosystem approach (Table 1). The Biogas Boat is a floating, mobile restaurant that converts organic waste into fertilizer and biogas, which it then uses for cooking meals. The project involved five differ- ent supporting partners, crowdfunding, academic research facilities, a diverse project team, and a unique set of urban assets, including Amsterdam's canals, disused boats, and a post-industrial site.

Table 1. Urban waste innovation in Amsterdam

\begin{tabular}{ll} 
Dimension & Description \\
\hline Technology & Biogas Boat \\
\hline Finance & - Crowdfunding: $€ 10,000$ \\
& - Municipality $€ 10,000$ \\
& - Foundation: $€ 30,000$ \\
& - Tosearch funds: $€ 10,000$ \\
&
\end{tabular}

Brief "In the Biogas Boat, we are building a biodigester that converts all the organic waste produced at De Ceuvel [Café] into biogas, which can be used to cook with. ... In the near future, she will visit festivals to collect organic matter to convert into gas and fuel, thereby showing a larger audience the great potential of waste." (Biogas Boat, 2018)

\begin{tabular}{lll}
\hline Project Team & - Simme Andriesma \\
& (Entrepreneur/Designer) \\
& - Rolf Steenwinkel (Amsterdam Energie) \\
& Enki Energy Company (Technology \\
& Specialist) \\
& - Huib Koel (Boat Designer) \\
\hline Project Partners & - City of Amsterdam \\
& - Stichting DOEN Foundation \\
& - Triodos Foundation \\
& BAM Construction \\
& Amsterdam University of Applied \\
& Sciences (HvA)
\end{tabular}

\begin{tabular}{ll}
\hline Deployment & One boat at De Ceuvel Café \\
\hline Challenges & $\begin{array}{l}\text { "We are still waiting for the permit to be } \\
\text { issued for the project, before putting } \\
\text { everything together. The permit process has } \\
\text { been very complicated, and we are still not } \\
\text { completely sure whether we will get it." } \\
\text { (Project team member) }\end{array}$ \\
& $\begin{array}{l}\text { "Our main aim is to carry out this first } \\
\text { experiment and make it work on De Ceuvel. } \\
\text { The aim is to inspire people to see what can } \\
\text { be done with our waste locally. Secondly, we } \\
\text { will share the lessons we learned from the } \\
\text { project with, for example, the local water } \\
\text { authority. They will be able to use these } \\
\text { lessons for local bio-digestion projects on a } \\
\text { neighbourhoodscale." (Co-founder of Café } \\
\text { de Ceuvel) }\end{array}$
\end{tabular}




\section{From Organizations to Organizational Fields: The Evolution of Civic Innovation Ecosystems Matthew Claudel}

Contrary to traditional $R \& D$, the urban innovation ecosystem process is inherently ad hoc, shaped by local challenges, resources, and stakeholders (Cooke, 2016; Gascó, 2016). This presents two primary challenges. The first is aggregating the necessary tools and resources, including funding, hardware prototyping facilities, collaborators, data for benchmarking, or regulatory approval to deploy prototypes (Leminen et al., 2012; Schaffers \& Turkama, 2012). The second, closely related, challenge is effective collaboration across stakeholder groups, each with distinct "languages" (Bakici et al., 2013; Wareham \& Almirall, 2011). For example, a policy maker and a data scientist may not share a mental model for traffic systems, despite both working on autonomous cars. Cross-sectoral innovation therefore requires translation. Biogas Boat merged traditionally siloed sectors: academia (organic waste processing technology), De Ceuvel Café (restaurant operations), government (waste management regulation), in addition to the core team (experts in energy systems, design entrepreneurship, and boat design) and the public, through a crowdfunding campaign and volunteer build-teams. This project demonstrates the social and recombinant nature of innovation: it is the result of local networks (Schumacher \& Feurstein, 2007).

Many academics have contemplated the structure of innovation networks and have examined the role of "innovation intermediaries", which translate projects from collaborative exploration to innovative exploitation (Cooke, 2008; Leminen et al., 2012; Nilsson \& Sia-ljungström, 2013; Wareham \& Almirall, 2011). These intermediaries perform aggregation and mediation functions: they consolidate resources (financial, technological, and talent), and translate between knowledge bases (through convening, consultancy, and best practice). Specific to urban technology, two general models have emerged to fill the hub role: living labs and innovation integrators (Bakici et al., 2013; Foster \& Iaione, 2016). Municipal policy makers seeking to create an urban innovation ecosystem launch such an organization (Gascó, 2016; Juujarvi \& Lund, 2016).

Living labs have origins in academia and industry, while innovation integrators began as brokers of civic technology in city governments, such as e-government platforms, IT infrastructure, and smart sensors (see the next section for a short history of the two organization types). Yet both share the hub organizational model (Figure 1). They support initial ideation, or, "exploration" - as both entirely new projects and the recombination of existing resources - and support subsequent implementation or "exploitation" (Cooke, 2008, 2016;
March, 1991). Many offer an area for experimentation or actively organize programs and innovation challenges. By engaging their contexts, and publicly demonstrating examples of civic technology, these organizations "perform context-based experimentation in order to generate new socially negotiated meanings for products and services" (Wareham \& Almirall, 2011). The surrounding ecosystem is then defined by this central actor. "According to the literature, the ecosystem structure is determined by the position and the role that the 'ecosystem hub' - or the individual organization that directs the ecosystem - plays" (Visnjic et al., 2016).

\section{Living Labs and Innovation Integrators}

Building on a longer history in academia, the contemporary manifestation of the living lab concept was articulated by William J. Mitchell, Kent Larson, and Alex (Sandy) Pentland at the Massachusetts Institute of Technology (MIT) in the early 2000s. According to its website (livinglabs.mit.edu): "MIT Living Labs brings together interdisciplinary experts to develop, deploy, and test - in actual living environments - new technologies and strategies for design that respond to this changing

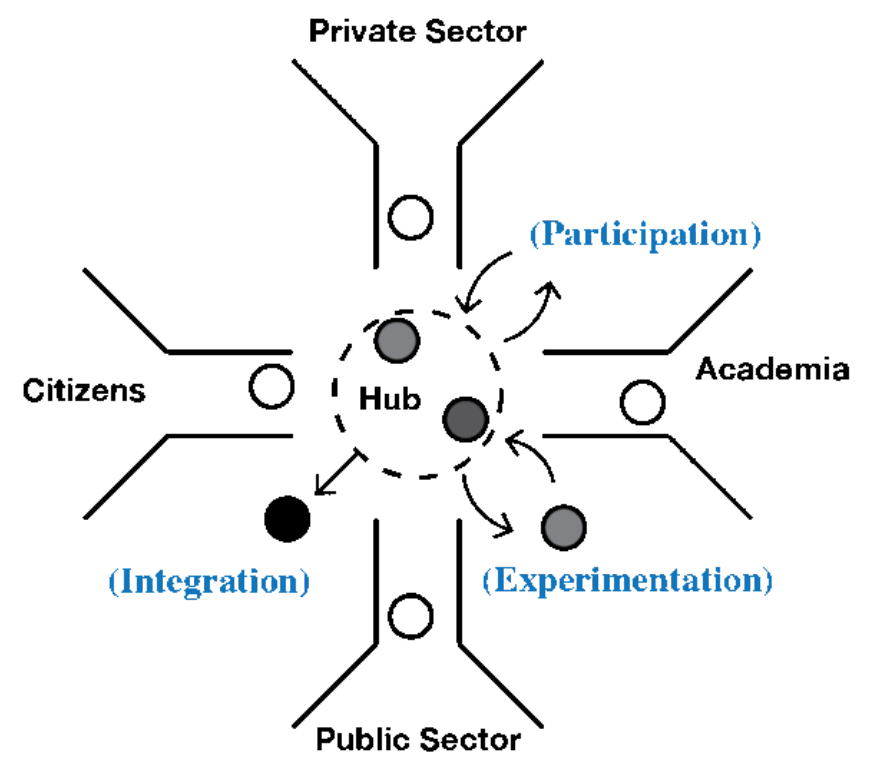

Figure 1. The Innovation Ecosystem Hub Model. The hub centralizes innovation activity by aggregating resources and brokering between different sectors. Circles indicate projects at various levels of completion: participatory problem definition; experimental project development; and integrative product deployment. Figure adapted from Curley and Salmelin (2013) and Visnjic and co-authors (2016). 


\section{From Organizations to Organizational Fields: The Evolution of Civic Innovation Ecosystems Matthew Claudel}

world. Our work spans in scale from the personal to the urban, and addresses challenges related to health, energy, and creativity."

Subsequent implementation happened primarily in Europe, where living labs gained significant political legitimacy in 2006 from the Finnish Presidency. The Helsinki Manifesto (Finland's EU Presidency, 2006) called for "a new European R\&D and innovation system", and framed living labs as a crucial "paradigm shift for the whole innovation process". The statement was endorsed by the European Union (EU) and, in the same year, existing organizations were formally linked through the EU-sponsored European Network of Living Labs (ENoLL; enoll.org). One of the primary purposes of the network was to systematize the many organizations - which had quickly become heterogeneous in structure and practice (Mulder et al., 2008) - around a common set of principles. A concomitant report from the European Commission defined the living lab as "a userdriven open innovation ecosystem based on a business-citizen-government partnership that enables users to take an active part in the research, development and innovation process for new services, products and societal infrastructures" (Peltomaki, 2008). The model is based on testing in real-world environments, citizen engagement, and linking stakeholders - as enumerated in the original report. "Involving all relevant players of the value network via partnerships between business, citizens, and government... Allowing for early assessment of the socio-economic implications of new technological solutions by demonstrating the validity of innovative services and business models" (Peltomaki, 2008). For the purposes of this article, I consider labs that are recognized as at least "Adherent Members" of ENoLL, which is its most open membership class.

The innovation integrator is equally active, but less cohesively defined. It is more directly associated with municipal governments, often beginning as either a "change unit" or a technology group. These brokering organizations span into and out of city hall, bridging a gap between technical capacity and practical deployment opportunities. Bakici and colleagues (2013) describe them as autonomous "public innovation intermediaries" that work in close partnership with businesses, academia, government, and citizens. "[The] role of public innovation intermediaries is to build networks of organizations and then be the first to attract all the project ideas from these networks... In general, city halls provide financing and incentives for projects and/or legislative support, such as offering opportunities for experimentation" (Bakici et al., 2013). A number of case studies have documented the practices of these intermediaries, for example, how Boston Mayor's Office of New Urban Mechanics pioneered the integration of digital systems into government (Crawford \& Walters, 2013) and how Forum Virium in Helsinki sparked ideation for civic problems through open data, hackathons, crowdsourcing, and public innovation contests (Almirall et al., 2014). These innovation integrator organizations experiment with new technologies, through maintaining a local network of actors, directly engaging with citizens, and co-developing with citizens and with firms.

\section{Case Design with Co-Existing Organizations}

Hundreds of living labs and innovation integrators are in operation around the world, and a critical evaluation is needed to understand their impact on urban innovation ecosystems. Conceptual and semantic ambiguity has frustrated research on place-based, but technologically agnostic, "territorial innovation systems" (Moulaert \& Sekia, 2003). Research focused on specifically urban technology has examined the practices and effectiveness of living labs and innovation integrators independently (Cohen et al., 2016), but none has compared the two. Overarching surveys of the urban technology field have mapped academic disciplines, practical methods, and trends in the discourse (Brynskov et al., 2014).

Comparative research remains vexed. On one hand, analysis of a single organization, or the innovation dynamics of a single city, can provide thorough information (e.g., Juujarvi \& Lund, 2016; Scholl \& Kemp, 2016; Snow et al., 2016), but insights are difficult to generalize. On the other hand, comparisons of the same organization type across cities can lead to more general conclusions (e.g., Gascó, 2016; Bakici et al., 2013), but must address the problem of comparability across unique contexts, and more importantly, against the other organization type. Broadly speaking, this is the challenge of applying heuristic tools to cities - a well-recognized wicked problem for urban science (Webber \& Rittel, 1973). To overcome these hurdles, I both exploit and investigate the phenomenon of co-existence, allowing us to observe how each organization type contends with the same set of local conditions. The central question of this article therefore becomes a useful analytical tool.

The panel of nested cases (Table 2) is further structured to disentangle factors that are specific to each city and those that are shared among cities (Flyvbjerg, 2006; Yin, 2013). This approach bridges the depth of small case 


\section{From Organizations to Organizational Fields: The Evolution of Civic Innovation Ecosystems Matthew Claudel}

Table 2. Nested cases and interviewees (LL = living lab; ii = innovation integrator)

\begin{tabular}{|c|c|c|}
\hline City \& Organization & Interviewee & Title \\
\hline \multirow[t]{3}{*}{ Aarhus (Denmark) } & Line Gerstrand Knive & $\begin{array}{l}\text { Office of the Mayor, Aarhus Municipality; Co- } \\
\text { founder, Smart Aarhus }\end{array}$ \\
\hline & Mads Peter Laursen & Godsbanen, Founder, Director \\
\hline & Michael Troelsen & $\begin{array}{l}\text { Urban Innovation, Office of Environment \& } \\
\text { Technology, Aarhus Municipality, Director }\end{array}$ \\
\hline \multirow{2}{*}{ LL: Digital Urban Living Labs (DULL) } & Jesper Algren & Head of Central Denmark Regions ICT \\
\hline & Martin Brynskov & Professor, Aarhus University; Chair, DK Smart City \\
\hline \multirow[t]{4}{*}{$i i: I T K L a b$} & Bo Fristed & Founder and Director, ITK; Aarhus CIO \\
\hline & Anne Vest Hansen & Head of ITK Lab \\
\hline & Louise Overgaard & Development Consultant, ITK \\
\hline & Dennis Borup Jakobsen & Project Manager, ITK \\
\hline Amsterdam (Netherlands) & Ger Baron & Chief Technology Officer, City of Amsterdam \\
\hline \multirow[t]{2}{*}{ LL: Urban Management Field Lab } & Willem van Winden & $\begin{array}{l}\text { Professor, University of Applied Sciences Amsterdam } \\
\text { Board Member, Urban Lab }\end{array}$ \\
\hline & Robert van den Hoed & Professor, University of Applied Sciences Amsterdam \\
\hline \multirow[t]{2}{*}{ ii:Amsterdam Smart City } & Maaike Osieck & Head of Communications \& Engagement \\
\hline & Vivienne Bolsius & Business Development Manager \\
\hline Barcelona (Spain) & Gerardo Pisarello Prados & Deputy Mayor, Barcelona \\
\hline LL: i2Cat & Josep Paradells Aspas & Director, i2Cat \\
\hline \multirow[t]{2}{*}{ ii: Barcelona Digital City } & Joan Batlle Montserrat & Asst. Director, Dept. Creativity \& Innovation \\
\hline & Anna Majo & $\begin{array}{l}\text { Digital Innovation Technical Director, Barcelona } \\
\text { City Council }\end{array}$ \\
\hline Copenhagen (Denmark) & Morten Kabell & Mayor for Environment \& Tech, Copenhagen \\
\hline \multirow{2}{*}{$\begin{array}{l}\text { LL: National Green Lab for Lighting \& } \\
\text { Smart Urban Technologies (DOLL) }\end{array}$} & Kim Bostrøm & Head and CTO of DOLL; CTO Gate 21 \\
\hline & Teddy Larson & Senior Project Manager, DOLL \\
\hline ii: Copenhagen Solutions Lab & Marius Sylvestersen & Program Manager, Copenhagen Solutions Lab \\
\hline
\end{tabular}




\section{From Organizations to Organizational Fields: The Evolution of Civic Innovation Ecosystems Matthew Claudel}

studies with the breadth of larger surveys (Storper et al., 2015). The cities are comparable along factors of the analytical logic: for example, cities host all stakeholder types (including university and large industry), and each has an open data platform and embedded digital infrastructure (enabling various forms of experimentation and participation).

Conversely, variation between cities - across specific factors that relate to the analytical logic - ensures that no single variable is independently responsible for the observed outcomes. Given the focus of this study, the factors that could potentially influence innovation dynamics are:

- Population: this factor defines the local market size and attractiveness to international businesses.

- Political status as a capital: this factor may impact a city's access to national or international funding for public projects.

- Nation (regulation and trade, economy-type, language, education system, etc.): this factor may define innovation activity as well as scale-up opportunities the panel therefore includes cities within the same country, and cities across different countries).

- City government (how long the administration has been in office) and structure (e.g., a "strong-mayor system" versus a council system): these factors dictate the creation, communication, and realization of a civic vision.

\section{Analysis}

Organization-level evaluation of eight cases

I first examined each organization individually, using interviews with leadership, site visits, and basic data. The analysis considered:

- Organizational structure (internal staff and organization; external partnerships)

- Primary mode of operations (what specific actions the organization carries out)

- Key projects (most prominent or typical project of the organization)

- Outcomes and development (results, sustainability, and evolution over time)
Table 3 briefly characterizes the structure and operational model of each organization. Furthermore, it lists two projects from each organization that typify its work and gives a broad overview of each organization's development over time.

In these eight cases, no organization successfully and sustainably performs as a hub to the ecosystem. Over time, these eight organizations have followed one of three trajectories:

1. Specialize: focus operations to achieve a targeted outcome

(3 cases: UM Field Labs, DOLL, i2Cat)

2. Split: multiple sub-organizations or project tracks each specialize

(3 cases: CPH Solutions Lab / Street Lab, ITK Lab / Street Lab, BCN's urban test site)

3. Move to a mediating role: assume a more abstract platform role

( 2 cases: AMS Smart City, DULL becomes Smart Aarhus)

\section{Specialize: focus operations to achieve a targeted out- come}

Financial constraints have pushed i2Cat to specialize and focus on industry contracts: "now most of our projects are for companies. They want to keep the IP... We can develop solutions and sell you this knowledge" (Josep Paradells Aspas). Specialization has eclipsed the living lab approach itself, to the point that "the living lab methodology is not applied to all projects. In some cases, the company has clear ideas about what they want. They know how to validate the success."

Similarly, DOLL "is a marketplace for procurement. Our goals are: 1. Help public decision-makers with a business case and evidence in a non-mature market, so they can do intelligent spending; 2 . Help industry test integration and start making solutions with [new] technology. There is a big business opportunity" (Kim Bostrøm). DOLL's tests inform technology development (e.g., engineering specifications) but are not a vehicle for user feedback. Currently, “we don't have a way of collecting what they think about it. In the future, we imagine user focus groups." Though DOLL provides infrastructure for testing, it is not involved with ideation or technology itself - rather, the leadership frames DOLL as "an open-air catalogue" with a strong model for industry and municipal membership. 


\section{From Organizations to Organizational Fields: The Evolution of Civic Innovation Ecosystems Matthew Claudel}

Table 3. The eight organizations - four living labs and four innovation integrators - and their host cities

\begin{tabular}{|c|c|c|c|c|}
\hline Organization & Structure & Operations & Projects & Outcomes and Development \\
\hline $\begin{array}{l}\text { UM FieldLab } \\
\text { Amsterdam }\end{array}$ & $\begin{array}{l}\text { HvA partners with } \\
\text { communities, } \\
\text { businesses and gov. to } \\
\text { find local challenges, } \\
\text { and apply solutions }\end{array}$ & $\begin{array}{l}\text { Co-creation, academic } \\
\text { research, and } \\
\text { neighbourhood } \\
\text { application of social } \\
\text { science }\end{array}$ & $\begin{array}{l}\text { Youth \& Debt } \\
\text { Climate Street }\end{array}$ & $\begin{array}{l}\text { Mixed outcomes, generally projects have limited } \\
\text { scale (only academic, or application at } \\
\text { neighbourhood-scale); now doing research with, } \\
\text { and about, AMS Smart City }\end{array}$ \\
\hline $\begin{array}{l}\text { DOLL } \\
\text { Copenhagen }\end{array}$ & $\begin{array}{l}\text { Tech prototype testing } \\
\text { in a suburban office } \\
\text { park; industry } \\
\text { membership model, } \\
\text { and procurement } \\
\text { program with cities }\end{array}$ & $\begin{array}{l}\text { Provide testing } \\
\text { infrastructure to } \\
\text { members; an "open air } \\
\text { catalogue" for buyers; } \\
\text { networking }\end{array}$ & $\begin{array}{l}\text { Smart Urban } \\
\text { Services } \\
\text { Lighting } \\
\text { Metropolis }\end{array}$ & $\begin{array}{l}\text { Strong outcomes; a robust financial model, high- } \\
\text { tech projects, corporate and civic partnerships, } \\
\text { and a growing global network; now expanding } \\
\text { into other urban tech (integrating systems). } \\
\text { Considering expanding to other countries with a } \\
\text { franchise model. }\end{array}$ \\
\hline $\begin{array}{l}\text { i2Cat } \\
\text { Barcelona }\end{array}$ & $\begin{array}{l}\text { Non-profit "research } \\
\text { and innovation center"; } \\
\text { public and private } \\
\text { sector contracts }\end{array}$ & $\begin{array}{l}\text { Develop early-stage } \\
\text { hardware and software } \\
\text { prototypes, "from need } \\
\text { to solution", but does } \\
\text { not bring them to } \\
\text { market }\end{array}$ & $\begin{array}{l}\text { Sentillo } \\
\text { Platform } \\
\text { Mobile } \\
\text { Payment } \\
\text { System }\end{array}$ & $\begin{array}{l}\text { Mixed outcomes; financial instability (majority of } \\
\text { funding from public grants) has led to prioritizing } \\
\text { corporate contracts; public funding limits team } \\
\text { size and compensation; now working with BCN } \\
\text { Digital City to set up CatLab, a fab lab network of } \\
\text { maker libraries }\end{array}$ \\
\hline $\begin{array}{l}\text { CPH } \\
\text { Solutions Lab } \\
\text { Copenhagen }\end{array}$ & $\begin{array}{l}\text { PPP with city gov. and } \\
\text { companies, to test, } \\
\text { procure and scale; } \\
\text { finding tech solutions to } \\
\text { urban challenges and } \\
\text { applying them in city } \\
\text { departments }\end{array}$ & $\begin{array}{l}\text { Managing Street Lab, a } \\
\text { downtown tech testing } \\
\text { site; networking; } \\
\text { creating a new model } \\
\text { for tender and } \\
\text { procurement; open } \\
\text { data platforms }\end{array}$ & $\begin{array}{l}\text { Smart Parking } \\
\text { Crowd-source } \\
\text { Bike Lane } \\
\text { Mapping }\end{array}$ & $\begin{array}{l}\text { Mixed outcomes; disparity of the financial model } \\
\text { and topic-definition (company-led tech testing } \\
\text { vs. community-defined civic challenges) has } \\
\text { caused a split into two project types (Street Lab } \\
\text { and Solution Lab); now focusing on both tech } \\
\text { products and a "new approach" to real-world } \\
\text { challenges }\end{array}$ \\
\hline $\begin{array}{l}\text { ITKLab } \\
\text { Aarhus }\end{array}$ & $\begin{array}{l}\text { An innovation team } \\
\text { based in the Culture } \\
\text { and Citizen Services } \\
\text { Dept. that spans across } \\
\text { city gov; a large team } \\
\text { with diverse skills and } \\
\text { varied projects }\end{array}$ & $\begin{array}{l}\text { Citizen engagement; } \\
\text { tech prototype testing; } \\
\text { developing a proof-of- } \\
\text { concept, handing it off } \\
\text { to other departments or } \\
\text { companies; EU-funding } \\
\text { proposals }\end{array}$ & $\begin{array}{l}\text { Dokk1 \& } \\
\text { Digital Library } \\
\text { System } \\
\text { Drones for } \\
\text { City Services }\end{array}$ & $\begin{array}{l}\text { Strong outcomes; an increasingly large and } \\
\text { diverse team carries out projects in two } \\
\text { categories: tech-first (beginning with new tech } \\
\text { and finding civic applications) and problem-first } \\
\text { (beginning with challenges and finding tech); } \\
\text { now focused on internal change for city hall; } \\
\text { starting a downtown street lab for prototype } \\
\text { testing, inspired by CPH Solutions Lab }\end{array}$ \\
\hline
\end{tabular}

\begin{tabular}{|c|c|c|c|c|}
\hline $\begin{array}{l}\text { AMSSmart City } \\
\text { Amsterdam }\end{array}$ & $\begin{array}{l}\text { PPP with univ, city gov. } \\
\text { and companies to issue } \\
\text { challenges and create } \\
\text { solutions; industry } \\
\text { member model; } \\
\text { organization is } \\
\text { structured according to } \\
\text { urban challenge topics }\end{array}$ & $\begin{array}{l}\text { Program to embed in } \\
\text { industry } \\
\text { representatives in city } \\
\text { gov; online repository } \\
\text { of resources; foreign } \\
\text { delegation visits; active } \\
\text { networking }\end{array}$ & $\begin{array}{l}\text { CityZen } \\
\text { AMS Smart } \\
\text { City } \\
\text { Community \& } \\
\text { Smart City } \\
\text { Academy }\end{array}$ & $\begin{array}{l}\text { Strong outcomes; stable, lightweight model } \\
\text { organized on urban challenge topic areas (e.g. } \\
\text { waste, mobility, energy); now taking an } \\
\text { increasingly global focus (Smart City Academy, } \\
\text { online resources, delegation program \& City } \\
\text { Protocol for standards) }\end{array}$ \\
\hline $\begin{array}{l}\text { DULL } \\
\text { Aarhus }\end{array}$ & $\begin{array}{l}\text { Connecting regional } \\
\text { living labs, projects and } \\
\text { initiatives under one } \\
\text { umbrella, to access } \\
\text { larger funding }\end{array}$ & $\begin{array}{l}\text { Regular meetings, } \\
\text { networking, } \\
\text { collaborative projects } \\
\text { and EU funding } \\
\text { proposals }\end{array}$ & $\begin{array}{l}\text { Insero Living } \\
\text { Lab } \\
\text { Egmont } \\
\text { Hoejskolen }\end{array}$ & $\begin{array}{l}\text { Weak outcomes; DULL has ceased to exist, having } \\
\text { served its purpose - stakeholders are now } \\
\text { collaborating and securing funding without it; } \\
\text { DULL has effectively transitioned into Aarhus } \\
\text { Smart City and ITK }\end{array}$ \\
\hline $\begin{array}{l}\text { BCN Digital City } \\
\text { Barcelona }\end{array}$ & $\begin{array}{l}\text { Merger of the city's tech } \\
\text { and business dev } \\
\text { departments; public, } \\
\text { but works through } \\
\text { private partnerships }\end{array}$ & $\begin{array}{l}\text { Creates digital policy; } \\
\text { applies tech inside city } \\
\text { hall; manages a } \\
\text { participation platform } \\
\text { online and runs co- } \\
\text { creation workshops }\end{array}$ & $\begin{array}{l}\text { Vincles BCN } \\
\text { Open Budget }\end{array}$ & $\begin{array}{l}\text { Strong outcomes, in terms of tech policy } \\
\text { (Barcelona Digital Plan) internal change for city } \\
\text { hall (Open Budgeting), social innovation projects } \\
\text { (Vincles BCN); now innovating in civic processes } \\
\text { (tying innovation challenges, to the "urban lab" } \\
\text { test site, to new procurement models) }\end{array}$ \\
\hline
\end{tabular}




\section{From Organizations to Organizational Fields: The Evolution of Civic Innovation Ecosystems Matthew Claudel}

\section{Split: multiple sub-organizations or project tracks each specialize}

Owing to the success of their initial library innovation, ITK now has a broader scope, as a design-innovation team for the municipality. "In the past two years, we have been looked to as the innovation team for any department... Part of ITK are still doing things for libraries, but a growing part of us are doing things for other departments in the municipality" (Anne Vest Hansen). One portion of ITK will stay in this role, and another will soon launch a City Lab downtown, beside Dokk1, to prototype technology, gather data, test, and demonstrate public applications. "This is going to be a place to play football, go to a concert - and we have a lot of activities planned - but beneath the pavement, and in the light posts, we are putting up sensors [and digital infrastructure]" (Bo Fristed). Companies will be invited to install new technologies - for procurement by Aarhus municipality, or for other cities to visit. The diverging focus is apparent: another interviewee in ITK stated that, "for social engagement, it doesn't make sense to have a 'lab.' Would you ask some people for feedback and not others, who are outside the lab boundary? This is against the idea of engagement" (Louise Overgaard).

Aarhus City Lab is directly inspired by Copenhagen Street Lab, where the innovation integrator is "creating a common ground for linking city problems to the marketplace - harvesting private innovation for civic projects... It's a nice way of testing, and it makes it very easy to scale up - if it works in Copenhagen, in the Street Lab, it will work anywhere... We have aimed for ultra-realism in the way we have been building the lab. That gives us very realistic conditions when we are doing innovation projects and deploying new types of equipment" (Marius Sylvestersen). Street Lab has a clear focus on high-tech systems, and has a financially stable industry membership model. And yet, it is fracturing: the program manager stated "What I've been thinking about lately, that is quite new to us, is to turn away from doing innovation, just looking into tech stuff, and actually be driven by the needs of the city. That is a very different approach... In the beginning, we were tech-focused. Now we are looking for 'wicked problems.' We are turning away from tech stuff and really looking at the needs of the city - looking at citizens. This is a big shift. It's a new approach" (Marius Sylvestersen). Moving forward, CPH Street Lab will have two distinct project categories, with two different test sites, focus areas, funding streams, and partnerships.

\section{Mediate: assume a more abstract platform role}

Several organizations cease to actively engage in innovation projects and transition to providing a digital repository or connecting other organizations and stakeholders. AMS Smart City began with a public-private partnership between city government, the university of applied sciences, and energy companies, with the aim to innovate in the domain of energy and sustainability. The success of this project, CityZen, led to a broader focus on urban technology, but less specificity: the organization is not directly involved with projects. "Our day-to-day business is connecting people and organizations to work on urban challenges... We don't do project management, but we keep actively in touch, facilitating innovation... partners can connect, share knowledge, share projects, ask questions" (Maaike Osieck).

The organizations that specialize or split sacrifice their role as a central hub, whereas the organizations that mediate sacrifice project-specific activity (i.e., ideation, prototyping, deployment). In short, both organization types have evolved significantly from their original set of goals. Yet these four cities are widely recognized as global leaders of urban technology, and - with the exception of DULL - the eight organizations continue to be important agents of that success. How has each organization evolved over time, and in its urban context? To better understand the motivations for organizational change, it is necessary to consider the city as a whole, emphasizing the relationships between the co-located organizations, and among local stakeholders.

\section{Ecosystem-level: Four cities}

Considering the development of these four cities as ecosystems, the organizations have evolved for three primary reasons: 1) to manage threats to longevity by specializing; 2) the emergence of a common language and denser networks; and 3) the diffusion of technology across the city.

1. Longevity through specialization: In Barcelona, i2Cat focused on contract $R \& D$ for financial reasons, but also became a key partner for BCN Digital City, both to develop urban technology infrastructure and to set up new fab labs. "Now we have a new program called CatLabs, that is still being developed, together with the municipality... We provide training, support, tools [to] support the maker community" (Josep Paradells Aspas). In Copenhagen, DOLL focuses on commercial technology and industry membership, but contracts to the city and to CPH Solutions Lab. 


\section{From Organizations to Organizational Fields: The Evolution of Civic Innovation Ecosystems Matthew Claudel}

The latter has itself split into two project types in order to maintain conflicting outcomes of specialization: financial stability, partner relationships, and citizen engagement.

2. A common language and denser networks: DULL was initially a small group that pooled funding for projects in Aarhus. Several new organizations and events were soon founded, including Aarhus Smart City, Aarsome, City of Culture 2017, Media Architecture Biennale, and the annual Internet Week Denmark, which built awareness and a common language across the city. That is, the population developed a fluency with the idea of urban technology, or a "social imagination" (Archibugi, 2017). By that point, DULL had served its purpose - there was no longer a need for a translator. "I would say that the Digital Urban Living Lab, as a living lab, is dead. It's somehow finished... Cities are more mature with the smart city... [Aarhus] changed from a secretariat to calling it an ecosystem, like a network" (Jesper Algren). Most civic innovation activity now happens under the banner of Smart Aarhus, an independent entity that serves to brand projects and provide visibility. "The ecosystem works very well now, it's very well established. It's no longer 'innovation activities' with high risk - there are now a lot of business cases and use cases. It sounds more simple than it is, but it's all about networks" (Line Gerstrand Knive).

3. Diffusion of technology: In addition to social diffusion, urban technology is also spatially distributed throughout the city, and therefore intersects with daily life. "Copenhageners are used to being lab rats - they're used to seeing new things... This also spurs new innovations. We actually see several companies being formed. People say 'I see the city has these goals, now I can prove that,' and they develop a new solution" (Morten Kabell). A shared culture makes these demonstrations more effective, even generative of new ideas. It also and ensures longevity - ITK focuses more on building networks than on technology. "We are not selling a product, but doing projects - don't deliver a discrete thing, but create relationships. For a project to be agile and sustainably integrated, it must be based on relationships" (Louise Overgaard). In Aarhus, Barcelona, and Copenhagen, the living labs have recently partnered with the local innovation integrator on a downtown test site.

These cases show that living labs and innovation integrators are becoming increasingly interdependent with their local networks. Crucially, distributed innovation activity is happening without a strong-handed central broker. This clear pattern in the development of each city's ecosystem should lead us to question the hubbased model that anchors contemporary ecosystem theory: the literature assumes that a central hub is necessary to drive an open innovation process. To the contrary, I found that interaction among local businesses, citizens, organizations, and governments is happening organically (Figure 2). According to a city official in Aarhus, "We don't even think about it anymore. If we get an idea, we get in touch" (Line Gerstrand Knive). Stakeholders are connecting opportunistically project by project in response to challenges, opportunities, existing communities, technologies, etc. They are distributing their strengths and capacities, and sharing positive outcomes - constituting an "organizational field" (Storper et al., 2015) that renders the hub roles obsolete.

\section{Discussion: From an Organization to an Organizational Field}

The evolution of each organization in this study demonstrates that the hub model is obsolete. This conclusion is neither a challenge to innovation ecosystem theory nor a critique of innovation policy and its implementation. Rather, I suggest that we must extend the theoretical framework to account for two factors. First, to better account for socially-constructed institutions and how they enable a decentralized mode of innovation (Moulaert, 2001), a so-called "organizational field". Second, to better examine sociotechnical system change over time (Geels, 2004). My reading is evolutionary as well as ecosystemic.

Urban technology creates local culture, and local culture creates urban technology (Hall, 2003). The initial work of living labs and innovation integrators demonstrated the opportunity and value of civic innovation, as described by Huguenin and Jeannerat (2017). Over time, the number and scope of projects increased, creating cross-sector networks, shared culture, and mutual trust. The sociotechnical systems literature describes this activity in the context of a theory of change: "Niches are important, because they provide locations for learning processes, e.g. about technical specifications, user preferences, public policies, symbolic meanings. Niches are locations where it is possible to deviate from the rules in the existing regime. The emergence of new paths has been described as a 'process of mindful deviation'... This means that rules in technological niches are less articulated and clear-cut. There may be 


\section{From Organizations to Organizational Fields: The Evolution of Civic Innovation Ecosystems Matthew Claudel}
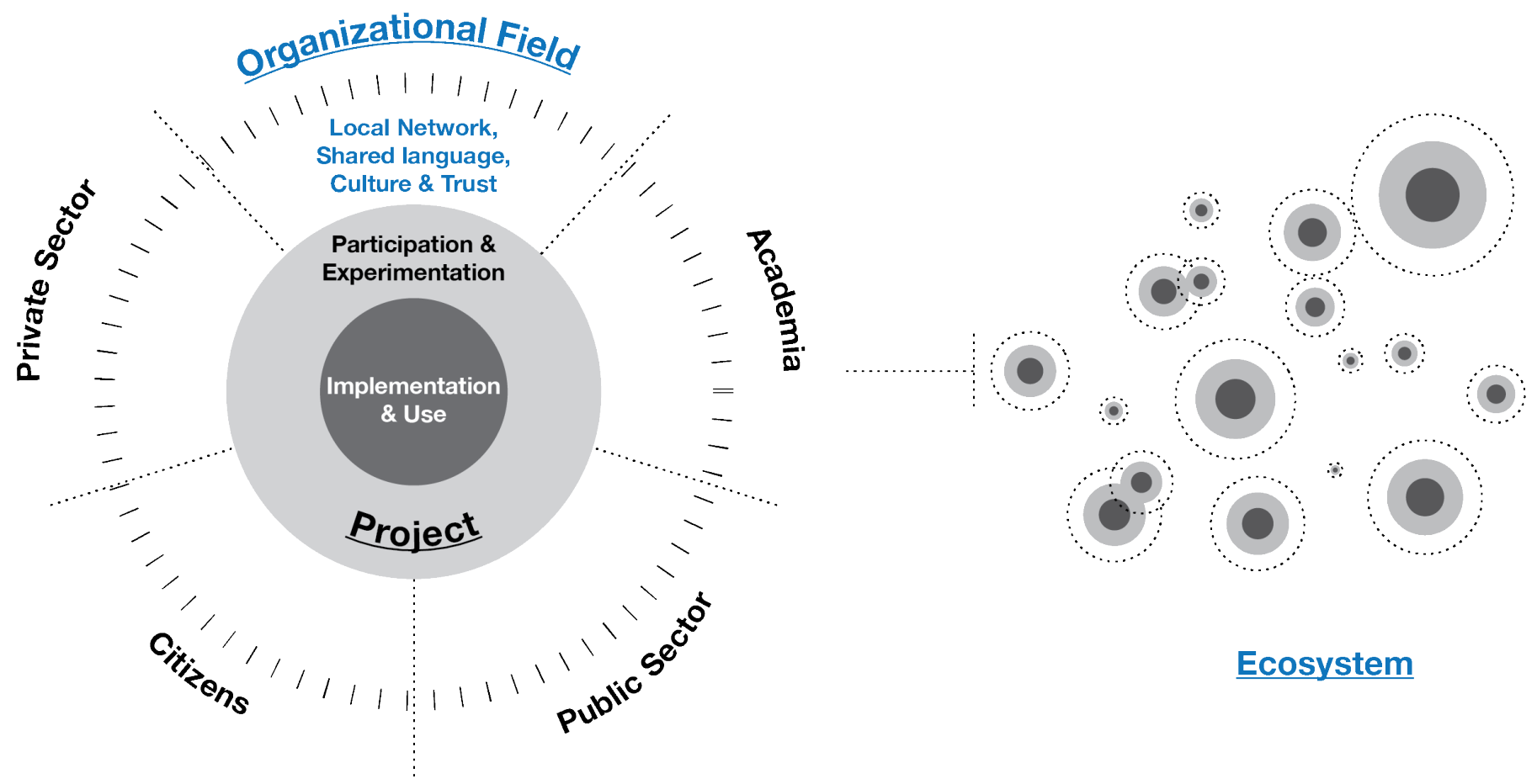

Figure 2. The Distributed Ecosystem Organization. Stakeholder groups converge around a project, through an organizational field of networks, shared language, culture, and trust. They collaborate on participation and experimentation, bringing a project to implementation and use. Many projects run simultaneously, and stakeholders cross into several different projects, share resources, or build capacities.

uncertainty about technical design rules and search heuristics, and niches provide space to learn about them" (Geels, 2004). The hubs were "niches" that allowed mindful deviation toward regime change. The organizational field then supports civic innovation by fostering participation and experimentation, as did the initial hub model.

\section{Participation}

As more and more citizens - particularly those who are not city planners, technologists, or entrepreneurs share a vision of civic innovation, participation becomes more natural. The community was initially activated for participatory ideation, for example, by BCN Digital City's challenges and Copenhagen Solutions Lab's bike mapping. Digital maps and co-design workshop-challenges are now intuitive and broadly accessible across the population. Many and varied stakeholders are using them, effectively becoming cocreators with city government. AMS Smart City began with a corporate member program, for which companies sent an employee to be embedded in city government - ostensibly acting as a liaison between the company and the city, but more importantly, building trust and shared goals. "The [link] speeds up things. That person has embedded knowledge of both sides, and that is core to the program" (Vivienne Bolsius). Not only does this allow more effective collaboration on projects during the program, but it also enables agile cooperation between the city and the firms in the future, when there may be higher stakes or unexpected conditions. "To achieve a future-proof city, the network is important" (Vivienne Bolsius). Through this program, energy companies have developed smart grid applications that better account for energy policy goals while achieving efficiency, for example. They are now working on a strategy for the complete transition from gas to fully electric utilities.

\section{Experimentation}

In their original state, living labs and innovation integrators served to mitigate the risk inherent to urban experimentation by providing a controlled test site or legal fail-safes, for example. An organizational field can alleviate much of the same risk, through dense networks, mutual trust, and repeated interactions. DOLL 


\section{From Organizations to Organizational Fields: The Evolution of Civic Innovation Ecosystems Matthew Claudel}

"ha[s] a standing relationship with the municipality. They grant us flexibility, and they are one of our consortium members... It is in an industrial area, so we can install what we like... It's ok to fail" (Kim Bostrøm). The relationship stands in place of a complex legal regime for regulatory exemptions or costly liability insurance.

A similar risk existed in De Ceuvel and the Biogas Boat. Flexibility in city zoning enabled De Ceuvel, trust among stakeholders de-risked the initial prototype, and local networks lent momentum to the collaborative project - all at the local scale. But the Biogas Boat is now impeded by national-level regulations. The project team leader states, "we currently have finished the base of the boat. We have also finished the container with digester system at a different location [in an academic lab facility]. However, we are still waiting for the permit to be issued for the project, before putting everything together. The permit process has been very complicated, and we are still not completely sure whether we will get it. The Dutch laws concerning bio-digestion are very strict, even small scale projects need an exemption." De Ceuvel and the Biogas Boat were enabled by a niche at the city level, and the hurdle of national-level regulation highlights the importance of place-based experimentation.

Godsbanen is a creative community in downtown Aarhus, home to artists and entrepreneurs, many of whom work in precariously stacked shipping containers and self-built studios. Despite its informal construction, the project is condoned by the city. Godsbanen is a story of "not having a lot of permissions, but just doing", notes Troelsen, a city official. "For me, it has always been a question of looking [the founder, Mads Peter Laursen] in the eye, and asking: 'The real necessary things, like fire risk, do you know how to manage them? And the rest, well, let's leave it for another day.' Because, otherwise, you cannot experiment, you cannot have these preliminary things. That's the reason why Godsbanen has been so great... an experimenting district. We've looked away on the rules and regulations, as long as they take care of each other" (Michael Troelsen). As a result of this experimentalist culture, Godsbanen has attracted passionate innovators who have produced a wide variety of new ideas.

The translation from urban experiments into urban systems crucially depends on the organizational field. In Aarhus, Dennis Borup Jakobsen is a drone pilot and enthusiast who was motivated to begin exploring applications of the technology for the public sector. His initial trials of drone imaging in emergency situations were al- lowed by police and fire departments, and they demonstrated clear gains in quality, speed, and cost efficiency. Rather than depending on ITK for technology development, however, those departments opted to start their own drone programs. ITK is assisting them with setup securing a budget, procuring a fleet of drones, and developing operations protocol - and will then cease to be involved. The initial deployment was enabled by mutual trust, and the collaborative capacity-building ultimately allows for more effective integration, in which police and fire departments own and operate their own systems. The project will result in a city-wide emergency response system and a publication of insights and technical protocols that can be used by any city in Denmark. Furthermore, the same employee is now pursuing a drone system for infrastructure monitoring, but it conflicts with national-level regulations. The current drone experiment was allowed to operate within a fixed radius, with supervision by an operator. The new proposal is for drones to fly linearly, over long distances and outside of city limits, to evaluate power lines. This could bring efficiencies and result in significant cost reduction, but it is prohibited by current national regulations. He is working to secure exemption in order to demonstrate a proof of concept, and he ultimately hopes to change national regulatory parameters. As in the case of the Biogas Boat, the local ecosystem enabled technology beyond what is contemplated in national regulation.

In Barcelona, city government is committed to integrating the results of participatory experiments. "We use the city as a lab: to experiment, to find new solutions for common problems. The municipality gets pilots on the streets, and companies are happy to sit down with users. [At first] this was just experimentation - learning, but no buying. Now, we are going beyond... We are linking design and experimentation to procurement" (Anna Majo). Open innovation challenges and neighbourhood-level engagement are directly connected to high-level policy, procurement and regulation - a process that is traditionally fraught with cumbersome (even prohibitive) procurement hurdles. This is evidence of a broader regime shift, beyond pilot and demonstration projects.

\section{Future Research}

The observed dynamics raise three questions that merit further research. The first is developmental: Must every urban innovation ecosystem mature through a hub phase, in the process of growing an organizational field? Though the hub role ultimately became obsolete, 


\section{From Organizations to Organizational Fields: The Evolution of Civic Innovation Ecosystems Matthew Claudel}

the initial niche of living labs and innovation integrators were crucial in fostering nascent projects. Without their early activity, a common vision may never have coalesced. This should be of primary concern to policy makers contemplating the appropriate support strategy for catalyzing an urban innovation ecosystem.

The second question is scale. A common culture, participation, word-of-mouth, trust-based experiments these are most effective as informal interactions at a small scale. A social construct of civic innovation will simply be easier in a smaller city. Tellingly, the most active city, Aarhus, is also the smallest. Problems of scale are evident in the divergence of local culture and national policies. Can trust-based, socially-constructed institutions exist robustly at a larger scale?

Finally, there is a question of formalization and the role of policy makers. The cases show evidence of the public sector building its own innovation capacity: granting area-specific regulatory exemption (Amsterdam); changing public procurement mechanisms and criteria (Barcelona); co-creating with citizens (Copenhagen); building tech-literacy across city government (Aarhus), and more. City governments appear to be acting in newly innovative ways using the tools at their disposal. Amsterdam, for example, has recently hired the original founder of AMS Smart City as the Chief Technology Officer, with a mandate of internal transformation in city government. The Deputy Mayor of Barcelona sees his role as "doing R\&D in politics - no one has done this before. We are learning by doing, and really doing things" (Gerardo Pisarello Prados). But this initiative is not without conflict. How can policy makers engage and support their urban innovation ecosystems in a way that is safe, equitable, legal, and replicable? Future research will investigate the changing role of the public sector, building on theories of public entrepreneurship (Foster \& Iaione, 2018; Klein et al., 2010; Ostrom, 1965, 2005).

\section{Conclusion}

A contemporary innovation ecosystem approach to urban technology leans on a hub organization: living labs and innovation integrators have been used to shepherd urban technology development. This article considered eight such organizations in cities where both models coexist. Over time, living labs and innovation integrators deviated from their original hub role, along one of three general paths: they specialized, they split into multiple entities, or they assumed a platform role (or closed entirely).

Yet, the four case cities remain at the global forefront of urban technology - each city has matured into a wellfunctioning innovation ecosystem. As conceptualized by Geels (2004), systems, actors, and institutions are distinct, and change occurs in their dynamic interaction. The living labs and innovation integrators provided an initial niche that fostered experimentation with a new (urban) technology category, its associated institutions, and its development pathways. Their success caused a regime shift - local stakeholders aligned around the topic and approach of civic innovation, forming an organizational field - and the ecosystem itself now serves certain core functions (enabling participation and experimentation) that were formerly filled by the hubs. This insight advances urban technology policy and scholarship: the hub model should be extended to better account for sociotechnical system development over time. It also highlights the role of the public sector, as both a supporter of the ecosystem and as an active innovator. The examined cases demonstrate that contemporary ecosystem support models have been useful niches to overcome initial hurdles, but that a sustained urban innovation ecosystem is a product of a distributed organizational field. 


\section{From Organizations to Organizational Fields: The Evolution of Civic Innovation Ecosystems Matthew Claudel}

\section{About the Author}

Matthew Claudel is a PhD candidate in the Department of Urban Studies and Planning at the Massachusetts Institute of Technology (MIT), and he is also affiliated with the MIT Lab for Innovation Science \& Policy and the MIT Center for Collective Intelligence. Matthew is a Co-Founder of MIT designX, where he is the Head of Civic Innovation. He is also the co-author of two books: Open Source Architecture and The City of Tomorrow.

\section{References}

Almirall, E., Lee, M., \& Majchrzak, A. 2014. Open Innovation Requires Integrated Competition-Community Ecosystems: Lessons Learned from Civic Open Innovation. Business Horizons, 57(3): 391-400. https://doi.org/10.1016/j.bushor.2013.12.009

Archibugi, D. 2017. The Social Imagination Needed for an InnovationLed Recovery. Research Policy, 46(3): 554-556. https://doi.org/10.1016/j.respol.2016.09.018

Bakici, T., Almirall, E., \& Wareham, J. 2013. The Role of Public Open Innovation Intermediaries in Local Government and the Public Sector. Technology Analysis \& Strategic Management, 25(3): 311-327.

https://doi.org/10.1080/09537325.2013.764983

Biogas Boat. 2018. The Biogas Boat: Cooking on Yesterday's Waste. De Biogasboot. Accessed June 6, 2018:

http://www.biogasboot.nl/english/\#the-biogas-boat

Booher, D. E., \& Innes, J. E. 2002. Network Power in Collaborative Planning. Journal of Planning Education and Research, 21(3): 221-236.

https://doi.org/10.1177/0739456X0202100301

Brynskov, M., Bermúdez, J. C. C., Fernández, M., Korsgaard, H., Mulder, I., Piskorek, K., Rekow, L., \& de Wall, M. 2014. Urban Interaction Design: Towards City Making. Amsterdam: Book Sprint.

Cohen, B., Almirall, E., \& Chesbrough, H. 2016. The City as a Lab. California Management Review, 59(1): 5-13. https://doi.org/10.1177/0008125616683951

Cooke, P. 2008. Regional Innovation Systems: Origin of the Species. International Journal of Technological Learning, Innovation and Development, 1(3): 393-409.

https://doi.org/10.1504/IJTLID.2008.019980

Cooke, P. 2016. The Virtues of Variety in Regional Innovation Systems and Entrepreneurial Ecosystems. Journal of Open Innovation: Technology, Market, and Complexity, 2(1): 13. https://doi.org/10.1186/s40852-016-0036-x

Crawford, S., \& Walters, D. 2013. Citizen-Centered Governance: The Mayor's Office of New Urban Mechanics and the Evolution of CRM in Boston. Cambridge, MA: Berkman Center for Internet \& Society. https://papers.ssrn.com/sol3/papers2.cfm?abstract_id=2307158
Curley, M. 2016. Twelve Principles for Managing Change. Nature, 533: 314-316.

https://doi.org/10.1038/533314a

Curley, M., \& Salmelin, B. 2013. Open Innovation 2.0: A New Paradigm. OISPG White Paper. Open Innovation Strategy and Policy Group (OISPG).

Desouza, K. C., \& Bhagwatwar, A. 2012. Citizen Apps to Solve Complex Urban Problems. Journal of Urban Technology, 19(3): 107-136.

https://doi.org/10.1080/10630732.2012.673056

Finland's EU Presidency. 2006. The Helsinki Manifesto. Finland's EU Presidency. Brussels: European Union.

Flyvbjerg, B. 2006. Five Misunderstandings About Case-Study Research. Qualitative Inquiry, 12(2): 219-245. https://doi.org/10.1177/1077800405284363

Foster, S. R., \& Iaione, C. 2016. The City as a Commons. Yale Law \& Policy Review, 34(2): 283-349.

Foster, S. R., \& Iaione, C. 2018. Ostrom in the City: Design Principles and Practices for the Urban Commons. In D. Cole, B. Hudson, \& J. Rosenbloom (Eds.), Routledge Handbook of the Study of the Commons: 1-24. Abingdon, UK: Routledge.

Gascó, M. 2016. Living Labs: Implementing Open Innovation in the Public Sector. Government Information Quarterly, 34(1): 90-98. https://doi.org/10.1016/j.giq.2016.09.003

Geels, F. W. 2004. From Sectoral Systems of Innovation to SocioTechnical Systems: Insights about Dynamics and Change from Sociology and Institutional Theory. Research Policy, 33(6-7): 897-920.

https://doi.org/10.1016/j.respol.2004.01.015

Gerometta, J., Häussermann, H., \& Longo, G. 2005. Social Innovation and Civil Society in Urban Governance: Strategies for an Inclusive City. Urban Studies, 42(11): 2007-2021.

https://doi.org/10.1080/00420980500279851

Hall, P. 2003. Cities in Civilization: Culture, Innovation, and Urban Order. Journal of Irish Urban Studies, 2(2): 1-15.

Huguenin, A., \& Jeannerat, H. 2017. Creating Change through Pilot and Demonstration Projects: Towards a Valuation Policy Approach. Research Policy, 46(3): 624-635. https://doi.org/10.1016/j.respol.2017.01.008

Juujarvi, S., \& Lund, V. 2016. Enhancing Early Innovation in an Urban Living Lab: Lessons from Espoo, Finland. Technology Innovation Management Review, 6(1): 17-26. https://timreview.ca/article/957

Klein, P. G., Mahoney, J. T., McGahan, A. M., \& Pitelis, C. N. 2010. Toward a Theory of Public Entrepreneurship. European Management Review, 7(10): 1-15. https://doi.org/10.1057/emr.2010.1

Kontokosta, C. E. 2016. The Quantified Community and Neighborhood Labs: A Framework for Computational Urban Planning and Civic Technology Innovation. SSRN Electronic Journal, 23(4): 67-84.

https://doi.org/10.2139/ssrn.2659896

Leminen, S., Westerlund, M., \& Nyström, A.-G. 2012. Living Labs as Open-innovation Networks. Technology Innovation Management Review, 2(9): 6-11.

https://timreview.ca/article/602 


\section{From Organizations to Organizational Fields: The Evolution of Civic Innovation Ecosystems Matthew Claudel}

March, J. G. 1991. Exploration and Exploitation in Organizational Learning. Organization Science, 2(1): 71-87. https://doi.org/10.1287/orsc.2.1.71

Moulaert, F. 2001. Globalisation and Integrated Area Development in European Cities. Oxford, UK: Oxford University Press.

Moulaert, F., \& Sekia, F. 2003. Territorial Innovation Models: A Critical Survey. Regional Studies, 37(3): 289-302. https://doi.org/10.1080/0034340032000065442

Mulder, I., Velthausz, D., \& Kriens, M. 2008. The Living Labs Harmonization Cube: Communicating Living Lab's Essentials. The Electronic Journal for Virtual Organization \& Networks, 10: 1-14.

Nilsson, M., \& Sia-ljungström, C. 2013. The Role of Innovation Intermediaries in Innovation Systems. In R. Rickert \& G Schiefer (Eds.), Proceedings in System Dynamics and Innovation in Food Networks: 161-180.

http://dx.doi.org/10.18461/pfsd.2013.1311

Ostrom, E. 1965. Public Entrepreneurship: A Case Study in Ground Water Basin Management. PhD Dissertation. Los Angeles, CA: University of California.

Ostrom, E. 2005. Unlocking Public Entrepreneurship and Public Economies. WIDER Discussion Papers. Helsinki, Finland: United Nations University World Institute for Development Economics (UNU-WIDER)

Peltomaki, A. 2008. Living Labs for User-Driven Open Innovation: An Overview of the Living Labs Methodology, Activities and Achievements. Brussels: European Commission, Directorate General for the Information Society and Media. https://doi.org/10.2759/34481

Schaffers, H., \& Turkama, P. 2012. Living Labs for Cross-Border Systemic Innovation. Technology Innovation Management Review, 2(9): 25-30.

https://timreview.ca/article/605

Scholl, C., \& Kemp, R. 2016. City Labs as Vehicles for Innovation in Urban Planning Processes. Urban Planning, 1(4): 89-102. https://doi.org/10.17645/up.vli4.749

Schumacher, J., \& Feurstein, K. 2007. Living Labs - The User as CoCreator. In Proceedings of the 13th International Conference on Concurrent Enterprising (ICE), Sophia Antipolis, France.

Shin, Y., \& Shin, D. 2016. Modelling Community Resources and Communications Mapping for Strategic Inter-Organizational Problem Solving and Civic Engagement. Journal of Urban Technology, 23(4): 47-66.

https://doi.org/10.1080/10630732.2016.1175826
Snow, C. C., Håkonsson, D. D., \& Obel, B. 2016. A Smart City Is a Collaborative Community: Lessons from Smart Aarhus. California Management Review, 59(1): 92-108. https://doi.org/10.1177/0008125616683954

Storper, M., Kemeny, T., Makarem, N. P., \& Osman, T. 2015. The Rise and Fall Urban Economies: Lessons from San Francisco and Los Angeles. Palo Alto, CA: Stanford University Press.

Stratigea, A., Papadopoulou, C.-A., \& Panagiotopoulou, M. 2015. Tools and Technologies for Planning the Development of Smart Cities. Journal of Urban Technology, 22(2): 43-62. https://doi.org/10.1080/10630732.2015.1018725.

Vanolo, A. 2014. Smartmentality: The Smart City as Disciplinary Strategy. Urban Studies, 51(5): 883-898. https://doi.org/10.1177/0042098013494427

Visnjic, I., Neely, A., Cennamo, C., \& Visnjic, N. 2016. Governing the City. California Management Review, 59(1): 109-140. https://doi.org/10.1177/0008125616683955

Voss, G., \& Carolan, N. 2012. User-Led Design in the Urban / Domestic Environment. Journal of Urban Technology, 19(2): 69-87. https://doi.org/10.1080/10630732.2012.698067

Wareham, J., \& Almirall, E. 2011. Living Labs: Arbiters of Mid- and Ground-Level Innovation. Technology Analysis \& Strategic Management, 23(1): 87-102. https://doi.org/10.1080/09537325.2011.537110

Webber, M. M., \& Rittel, H. W. J. 1973. Dilemmas in a General Theory of Planning. Policy Sciences, 2(4): 155-169. https://doi.org/10.1007/BF01405730

Yin, R. K. 2013. Case Study Research: Design and Methods (5th edition). Thousand Oaks, CA: SAGE Publications, Inc.

Citation: Claudel, M. 2018. From Organizations to Organizational Fields: The Evolution of Civic Innovation (cc) BY Systems. Technology Innovation Management Review, 8(6): 34-47. http://doi.org/10.22215/timreview/1163

Keywords: innovation systems, living lab, city, civic technology, innovation policy 


\section{Academic Affiliations and Funding Acknowledgements}

Canadà
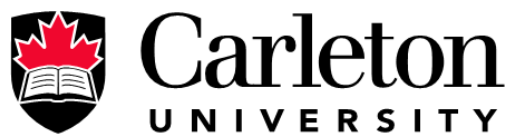

U N I V E R S I T Y

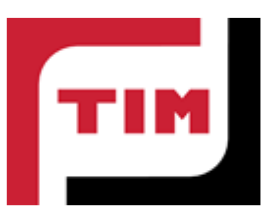

The Federal Economic Development Agency for Southern Ontario (FedDev Ontario; feddevontario.gc.ca) is part of the Innovation, Science and Economic Development portfolio and one of six regional development agencies, each of which helps to address key economic challenges by providing regionallytailored programs, services, knowledge and expertise.

- The TIM Review receives partial funding from FedDev Ontario's Investing in Regional Diversification initiative.

Technology Innovation Management (TIM; timprogram.ca) is an international master's level program at Carleton University in Ottawa, Canada. It leads to a Master of Applied Science (M.A.Sc.) degree, a Master of Engineering (M.Eng.) degree, or a Master of Entrepreneurship (M.Ent.) degree. The objective of this program is to train aspiring entrepreneurs on creating wealth at the early stages of company or opportunity lifecycles.

- The TIM Review is published in association with and receives partial funding from the TIM program. 